\title{
The effects of storing heat excess in a stone battery in a horticultural premise
}

\author{
Sławomir Kurpaska, Jakub Sikora, Krzysztof Mudryk, Hubert Latała and Jarosław Knaga \\ Faculty of Production and Power Engineering, University of Agriculture in Krakow, Poland
}

\begin{abstract}
This work presents the results of research connected with the flow of air through a stone battery. The research was carried out in a foil tunnel with a four-section stone battery. The battery deposit consisted of porphyry stone of $30-63 \mathrm{~mm}$ granulation. The process of inlet from the inside of a tunnel to a battery (manager using an algorithm) enabled the unbundling of heat storing cycle and the cycle of delivering the stored heat to the inside of the tunnel. The amount of heat and exchanged mass was described (in relation to the unitary surface and a particular cycle). Correlational equations were formed for the found values and they enable the calculation of a unitary heat stream and the masses of stone battery exchanged cycles.
\end{abstract}

\section{Introduction}

The concern for environment and the fear of attrition of fossil fuels sources boost the search for technical resolutions enabling heat saving. One of the premises in agricultural production are greenhouses and foil tunnels at which, in average conditions, demand for heat is around $2100 \mathrm{MJ} / \mathrm{m}^{2}$ (greenhouses) and $900 \mathrm{MJ} / \mathrm{m}^{2}$ (foil tunnels). These premises are characterised by high transparency and are prone to solar radiation. As a consequence, a conversion of solar radiation into the increase of heat occurs. The excess of heat is the cause of too high temperature inside the premises what results in an abnormal development of plants. There are some recommended values of air temperature which, depending on the type of plant, are located within 14 to $25^{\circ} \mathrm{C}$ [1]. Too high temperature favours the intensification of gas exchange causing the advantage of breathing process over photosynthesis. Too low temperature causes irregular development of above-ground parts of the plants. Abnormal temperature influences the speed, amount and quality of the crops of plants. Hence, ventilation of the premise is necessary. Therefore, the demand for heat increases. Storing the excess of heat in Energy batteries is an alternative solution leading to increased ventilation. The issue of storing excess heat in premises under covers was the subject of analyses and the developed systems concerned the issues of storing heat in bodies in which thermal capacity, phase changes (PCM) and chemical and photochemical changes were used. The results of experimental research of the theoretical analysis connected with heat storing in batteries filled with solid can be found in the works: [2- 5], and in liquid batteries in works $[6,7]$.

Analysing the research data, it is possible to note that the amount of stored and allocated heat to warm the premise depends not only on the temperature and the amount of inlet but also on the heat capacity of the deposit of the battery as well as the used overcame heat loss while storing. The research results in which the heat was stored in bodies undergoing phase changes (melting- coagulation, crystallizationdissolving, sublimation- resublimation, evaporationcondensation, boiling- condensation) and crystal structures' changes that go Ahead with obtaining and giving heat can be found in the works: [8-11]. The obtained results show that this method can be used successfully as means to lower the usage of heat in heated premises. Independent studies (carried out for areas of plural climate conditions) show thermal effects of liquids in ponds (together with temperature gradient) and the heat's complicity in an overall balance of the heated greenhouse. Kurt et al. [12] analysed the plural composition of liquid in a solar pond. They worked out a mathematical model describing temperature stratifications in the pond and verified the results in laboratory conditions and actual scale. Ozturk and Bascetincelik [13] have calculated the support foil tunnel heating with the heat stored in soil to annual savings in the heat usage showing the usefulness of this system in the examined climate conditions.

The presented overview unambiguously shows that the issue of storing heat excess from the inside of horticultural premise in batteries was the subject of analyses. The considered processes, however, 
concerned different climate conditions and premises with plural (constructive and geometrically) type of batteries. Therefore, the aim is to define the effects occurred while storing heat in stone battery through which the air flew in a controlled manner.

\section{Materials and method}

The research was done in a battery situated in a foil tunnel of $144 \mathrm{~m}^{2}$. The battery in the tunnel has $4 \mathrm{sec}-$ tions of $1.7 \times 11 \mathrm{~m}$ filled with stone deposit (augen stone of $30-63 \mathrm{~mm}$ granulation) on depth $0.7 \mathrm{~m}$. The outline of the stand is presented in fig. 1 .

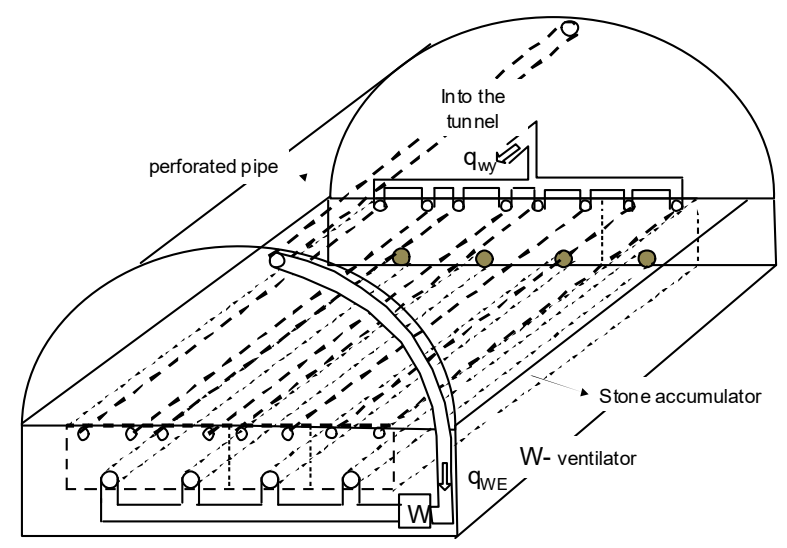

Figure 1. The outline of test stand

The following values were measured while carrying out research experiments:

- parameters of the surrounding climate: solar radiation volume- using LP PYRA 02AV pyranometer, wind speed- MAX $40 \mathrm{H}$ gauge, relative humidity and temperature of the air,

- parameters of the air flowing through a ventilator: speed ( Mini Air64 gauge) and air temperature

and humidity,

- parameters of the air flowing out of the battery: temperature and humidity,

- parameters inside the premise: air temperature and humidity.

The air temperature was measured using PT1000 gauges. Relative air humidity measurement was done using integrated HD 4917TC gauges. Managing the battery work (number of sections, battery work cycles) was realised thanks to an algorithm, where the managing signal was based on temperature difference: between the air being intaken by a ventilator and the air flowing out of the battery (charging cycle) and between the inside of the tunnel and the air flowing from the battery (discharging cycle). The stream of battery inlet was realize by means of radial ventilator cooperating with an inverter.

The amount of heat, in a differentia time $d \tau$ stored in a battery describes the following relation:

$$
d Q_{a k}=\frac{\pi \cdot d^{2}}{4} \cdot V_{p o w} \cdot \rho_{p o w} \cdot \int_{\tau_{1}}^{\tau_{1}+\tau}\left(i_{W E}-i_{W Y}\right) d \tau(1)
$$

The change in steam density in the air pumped through the battery as in the equation:

$$
d m_{H 2 O}=\frac{\pi \cdot d^{2}}{4} \cdot V_{p o w} \cdot \int_{\tau_{1}}^{\tau_{1}+\tau}\left(f_{W E}-f_{W Y}\right) d \tau
$$

where: $\rho_{\text {pow }}$-air density, $\mathrm{kg} / \mathrm{m}^{3} ; \mathrm{d}$ - measurement wire diameter, $\mathrm{m} ; i_{W E}, i_{W Y^{-}}$enthalpy of inlet $\left(i_{W E}\right)$ and outgoing $\left(i_{W Y}\right)$ from a battery, $\mathrm{kJ} / \mathrm{kg} ; f_{W E}, f_{W Y}$ irrespective humidity of inlet $\left(f_{W E}\right)$ and outgoing $\left(f_{W Y}\right)$ from a battery, $\mathrm{kg} / \mathrm{m}^{3}$.

To generalise the results, an average measurement of parameters' values ( $W_{\text {avg }}$ ) was done which determine the changes in the amount of stored heat and the changes in the amountof water in the battery. These values were calculated using their temporary values:

$$
W_{\text {avg }}=\frac{1}{\tau} \cdot \int_{\tau_{1}}^{\tau_{1}+\tau} w(\tau) d \tau
$$

All parameters necessary for determining those dependencies were determined for each cycle using the standard psychometric dependencies. The speed of inlet was measured in the wire of an internal diameter of $\mathrm{d}=0,3 \mathrm{~m}$.

\section{Results and discussion}

460 battery charging cycles and 410 battery discharging cycles were analysed. The time of charging cycles was located within 626 to $53637 \mathrm{~s}$; time of discharging was between 557 to 259241 s. The rest of the parameters were as follows:

a) Charging cycle: battery surface $\left(F_{a k}\right)$, $18.7 \leq F_{a k} \leq 74.8 \mathrm{~m}^{2}$; temperature of the surrounding $\left(t_{o t}\right),-6.2 \leq t_{o t} \leq 37.1^{\circ} \mathrm{C}$; solar radiation volume $\left(R_{s t}\right), \quad 5 \leq R_{s t} \leq 890 \mathrm{~W} / \mathrm{m}^{2}$; wind speed $\left(V_{\text {wiatr }}\right), \quad 0.1 \leq V_{\text {wiatr }} \leq 3.47 \mathrm{~m} / \mathrm{s}$; battery initial temperature $\left(t_{a k 0}\right), 2 \leq t_{a k 0} \leq 37.7^{\circ} \mathrm{C}$; battery final temperature $\left(t_{a k 1}\right), 6.7 \leq t_{a k 1} \leq 39.7^{\circ} \mathrm{C}$; air initial temperature $\left(\mathrm{t}_{\mathrm{WE}}\right), 11.1 \leq t_{\text {pow }} \leq 49.5^{\circ} \mathrm{C}$; air initial humidity $\left(\phi_{\mathrm{WE}}\right), 11 \leq \phi_{\mathrm{WE}} \leq 75 \%$; air final temperature ( $\left.\mathrm{t}_{\mathrm{WY}}\right), 6.4 \leq t_{\text {pow }} \leq 33.07^{\circ} \mathrm{C}$; air final humidity $\left(\phi_{\mathrm{WY}}\right), 29.4 \leq \phi_{\mathrm{WE}} \leq 94.4 \%$; inlet speed $\left(V_{\text {pow }}\right) 1.34 \leq V_{\text {pow }} \leq 4.72 \mathrm{~m} / \mathrm{s}$.

b) Discharging cycle: battery surface $\left(F_{a k}\right)$, $18.7 \leq F_{a k} \leq 74.8 \mathrm{~m}^{2}$; temperature of the surrounding $\left(t_{o t}\right),-11.1 \leq t_{o t} \leq 18.7^{\circ} \mathrm{C}$; wind $\operatorname{speed}\left(V_{\text {wiatr }}\right)$, $0.1 \leq V_{\text {wiatr }} \leq 2.79 \mathrm{~m} / \mathrm{s}$; battery final temperature $\left(t_{a k 1}\right), 4.1 \leq t_{a k 0} \leq 37.2^{\circ} \mathrm{C}$; air initial temperature $\left(\mathrm{t}_{\mathrm{WE}}\right),-4.55 \leq t_{\text {pow }} \leq 28.58^{\circ} \mathrm{C}$; air initial humidity $\left(\phi_{\mathrm{WE}}\right), 45.3 \leq \phi_{\mathrm{WE}} \leq 93.2 \%$; air final temperature $\left(t_{W Y}\right), 5.9 \leq t_{\text {pow }} \leq 33.71{ }^{\circ} \mathrm{C}$; air final humidity $\left(\phi_{\mathrm{WY}}\right), 31.7 \leq \phi_{\mathrm{WE}} \leq 91.5 \%$.

The range of changes of the inlet speed was in the same range as in battery charging cycles. Figure 2 shows the influence of 2 independent variables (the speed of inlet, inlet enthalpy) on the amount of stored 
heat in a unitary surface of a battery while charging cycle.

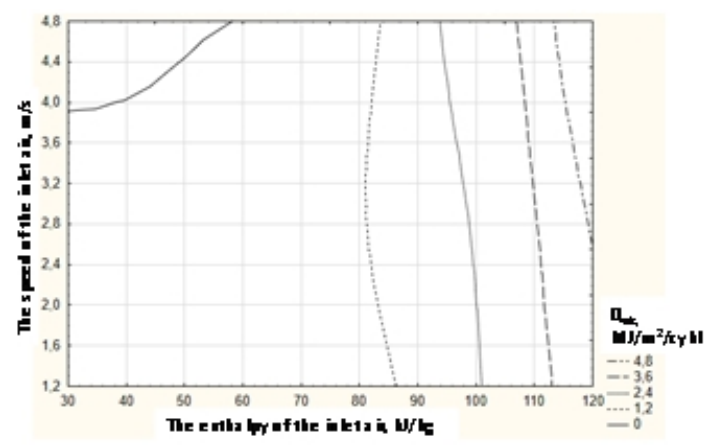

Figure 2 The influence of speed and enthalpy of inlet on the unitary amount of stored heat in a battery.

Figure 3 shows the influence of the same variables on the change of a mass of water absorber in the examined battery.

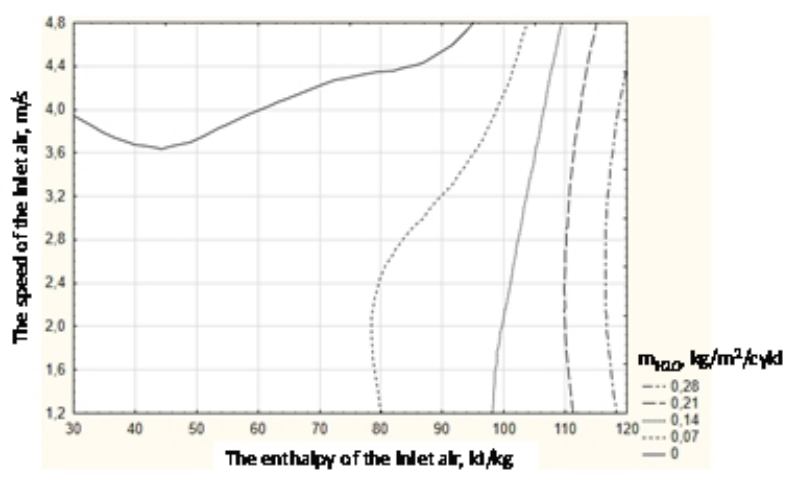

Figure 3. The influence of speed and inlet enthalpy on the change of water absorber in the battery while charging cycle.

As we can see, together with the increase of inlet enthalpy there is an increase of both the amount of heat and the mass of water in the battery. The increase in the inlet speed is not so clear, causing minor increase in the amount of stored heat (with higher enthalpy), in other cases- causing a negative effect both on the amount of stored heat and the amount of absorbed water. The entire range of changes in the amount of stored heat is within -3.9 to $4.7 \mathrm{MJ} / \mathrm{m}^{2} / \mathrm{cy}-$ cle. In the case of the change of absorbed mass of water it is -0.19 to $0.92 \mathrm{~kg} / \mathrm{m}^{2} /$ cycle.

Considering the time of particular cycles, the results were calculated into a unitary heat stream $(q)$ and mass $(m)$. The correlational equation mentions the relation (exponent model chosen on the basis of the highest value of resolving coefficient. This dependency was determined as nonlinear estimation using the quasi-Newton's method while a preserved coefficient of 0.001 ) takes the form of:

a) Heat stream $\left(\mathrm{W} / \mathrm{m}^{2}\right)$ :

$$
\begin{aligned}
& q_{\text {tad }}=-53.02 \cdot t_{a k 0}^{0.62}-24.57 \cdot V_{p o w}^{-1.9}+29.7 \cdot i_{W E}^{0.64} ; \\
& \mathrm{R}^{2}=0.72
\end{aligned}
$$

b) Mass stream $\left(\mathrm{g} / \mathrm{m}^{2} / \mathrm{min}\right)$ :

$$
\begin{aligned}
& m_{\text {tad }}=-0.079 \cdot t_{W E}+0.061 \cdot \phi_{W E}-0.169 \cdot V_{\text {pow }} \\
& \mathrm{R}^{2}=0.58
\end{aligned}
$$

Figures 4 and 5 show the course of the same variables while charging cycles.

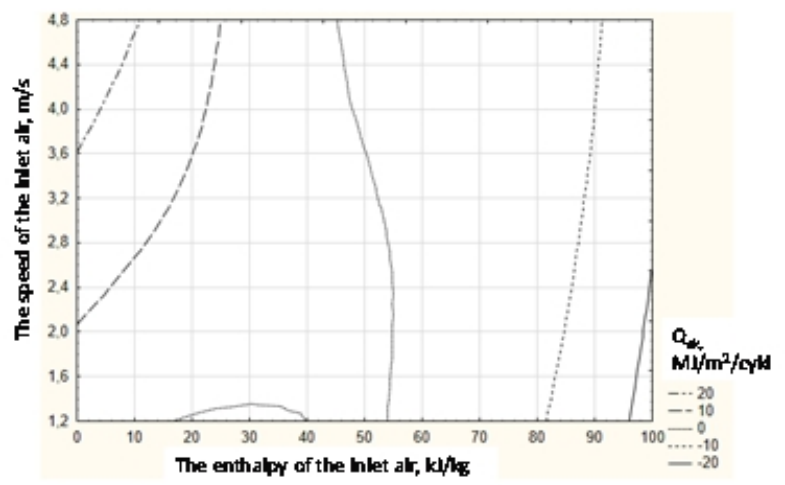

Figure 4. The influence of enthalpy and speed of inlet on unitary amount of absorbed heat from battery in its discharging cycle.

It can be noticed that the increase of enthalpy creates a negative effect on the amount of heat delivered from the battery to the inside of a foil tunnel. The increase in speed causes the increase of the amount of removed heat.

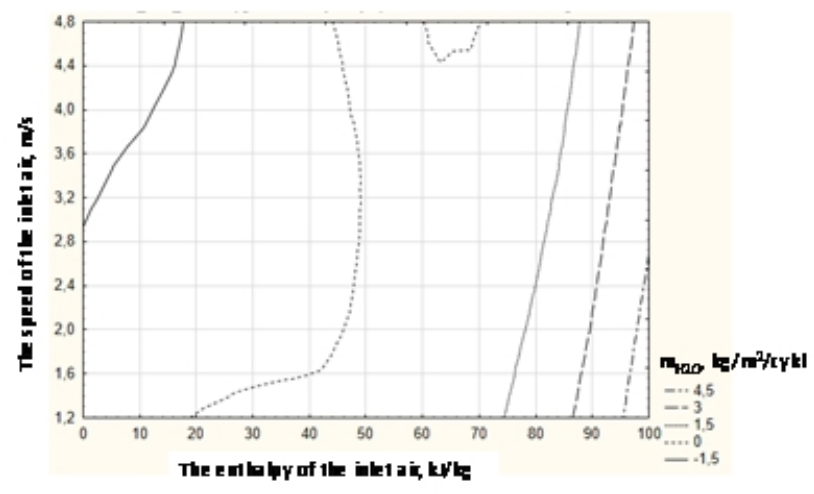

Figure 5. The influence of enthalpy and the speed on inlet on the amount of water mass removed from the battery in its discharging cycle.

The entire range of changes in the amount of heat delivered from the battery is within -21.5 to 28.1 $\mathrm{MJ} / \mathrm{m}^{2} /$ cycle. In the case of the mass of absorbed water, it is -6.17 to $4.96 \mathrm{~kg} / \mathrm{m}^{2} /$ cycle. Analysing these changes, we may state that the increase of inlet enthalpy causes an increase in the intensity of exchange of mass from the examined battery. This trend is reverse at the increase of speed. The observed negative values (both for the heat and the mass of water removed from the battery) shows that, for the existing conditions of carried out experiments, there is heat storing (fig. 4) and humidifying of the air coming out of the deposit. Alike before, correlational equations take the form of:

a) Heat stream $\left(\mathrm{W} / \mathrm{m}^{2}\right)$ :

$q_{\text {wod }}=21.18 \cdot V_{\text {wiar }}+15.83 \cdot t_{a k 1}+6.36 t_{o t}-24.63 \cdot t_{W E}-0.19 \cdot \phi_{W E}-268 \cdot V_{p o w}$

$\mathrm{R}^{2}=0.68$

b) Mass stream $\left(\mathrm{g} / \mathrm{m}^{2} / \mathrm{min}\right)$ : 


$$
\begin{aligned}
& m_{\text {rzzl }}=-0.101 \cdot t_{a k 1}+0.184 \cdot t_{W E}-0.0041 \cdot \phi_{W E}-0.0394 \cdot V_{p o w} \\
& \mathrm{R}^{2}=0.61
\end{aligned}
$$

The equations can be used in the range of given initial variables. Analysing the obtained results, we can unambiguously say that apart from the discussed issues connected with heat while charging process, there is a desiccation of air. Whereas during the discharging process, the air is humidified. The observed phenomena are a consequence of the inflow of humid air which causes vaporization or condensation of steam if it has contact with a surface of humid battery deposit. As a result, there is drainage (if condensation occurs) or humidifying (if vaporization occurs) of air coming from the deposit. The issues connected with heating (storing and heat recovering) are the result of both the occurring difference of temperatures between the flowing air and the temperature in deposit as well as the occurring steam thermodynamic transformation.

\section{Conclusions}

1 In the examined range of variables, the range of changes in the amount of stored heat while the charging process is within -3.9 to 4.7 , whereas while its discharging process, it is within- 21.5 to $28.1 \mathrm{MJ} / \mathrm{m}^{2} /$ cycle.

2 The range of changes in the amount of exchanged mass while air flowing through stone battery is within -0.19 to $0.92 \mathrm{~kg} / \mathrm{m}^{2} /$ cycle (battery charging), and while battery discharging, it is -6.17 to $4.96 \mathrm{~kg} / \mathrm{m}^{2} /$ cycle.

3 The correlational equations enabling the calculation of unitary heat stream and mass stream while analyses cycles of battery work can be used in the range of experiment factors change and consist of easily measured parameters connected with the flowing air, temperature of the deposit and the parameters of the surrounding air.

\section{Acknowledgements}

This research was financed by the Ministry of Science and Higher Education of the Republic of Poland

\section{References}

1. C.A. Campiotti, G. Morosinotto, G. Puglisi, C. Schettini, G. Vox, G.. Agriculture and Agricultural Science Procedia 8, (2016), 664 - 669

2. Bouhdjar, M. Belhamel, F. E. Belkhiri, A. Boulbina. Renewable Energy, 9, 1-4 (1996), 724- 728

3. Kurklu, S. Bilgin, B. Ozkan. Renewable Energy, 28, 5, (2003), 683- 697

4. W. Chen, W. Liu. Solar Energy, 76, 5 (2004), 623-633

5. S. Kurpaska, H. Latała. Renewable Energy, 35, 12 (2009), 2656- 2665
6. S. Kurpaska, H. Latała, D. Baran, P. Konopacki, R. Hołownicki. Agricultural Engineering, 3, 155 (2015), 47-57

7. D. Lindenberger, T. Bruckner, H. Groscurth, R. Kümmel. Energy, 25, 7 (2000), 591 -608

8. T. Ayhan, O. Comakli, K. Kaygusuz. Energy Conversion and Management 33, 3 (1992), 165- 173,

9. A.A. Badran, B. A. Jubran, E. M. Qasem, M. A. Hamdan. Applied Energy 58, 1 (1997), 5772

10. H.E.S. Fath. Energy Conversion and Management, 31, 2 (1991), 149- 155

11. S. Zhu, J. Deltour, S. Wang. Aquacultural Engineering 18, 3 (1998), 201-217

12. H. Kurt, M. Ozkaymak, K. Binark. Applied Energy 83, 4 (2006), 324-342

13. H. H. Ozturk, A. Bascetincelik. Biosystems Engineering 86, 2 (2003), 231-245 